\title{
37. EL SISTEMA DE FINANCIACIÓN DE LAS COMUNIDADES AUTÓNOMAS EN LA CONSTITUCIÓN
}

\author{
MIGUEL ÁNGEL COLLADO YURRITA \\ Profesor Titular de Derecho Financiero \\ Universidad Autónoma de Madrid
}




\section{SUMARIO}

I. EL SISTEMA DE FINANCIACIÓN AUTONÓMICA Y LA RESPONSABILIDAD FISCAL DE LAS COMUNidAdes Autónomas. - Il. La descentralización DEL GASTO PÚBLICO.-IIII. CONCLUSIONES 


\section{EL SISTEMA DE FINANCIACIÓN DE LAS COMUNIDADES AUTÓNOMAS EN LA CONSTITUCIÓN}

POR

MIGUEL ANGEL COLLADO YURRITA

Profesor Titular de Derecho Financiero

Universidad Autónoma de Madrid

I. EL SISTEMA DE FINANCIACIÓN AUTONÓMICA $Y$ LA RESPONSABILIDAD FISCAL DE LAS COMUNIDADES AUTÓNOMAS

Frecuentemente se ha dicho que el capitulo tercero del Título VIII de la Constitución relativo a las Comunidades Autónomas es impreciso e inconcreto.

Ello, que probablemente haya sido un acierto en cuanto que ha facilitado el difícil proceso de vertebración de un Estado autonómico que ha venido a suceder a otro fuertemente centralizado, es predicable asimismo de los preceptos que la Norma Fundamental dedica a la Hacienda Autonómica.

Como ha escrito PALAO, "los artículos 157 y 158 de la Constitución contienen una enumeración de las fuentes de ingresos de las Comunidades Autónomas tan genérica que en ella tiene cabida casi cualquier modelo de Hacienda Regional".

Aunque existen dos grandes modelos de organización federal o regional de distribución de los recursos entre la hacienda central y las haciendas subcentrales, el sistema de unión y el sistema de separación, lo 
cierto es que, en la práctica, en los Estados descentralizados, suele establecerse un sistema mixto, aun cuando en unos casos preponderarán los elementos de unión y, en otros, los elementos de separación.

También nuestra Carta Magna ha establecida un modelo mixto de financiación de las Comunidades Autónomas que gira en torno a dos principios esenciales: principio de coordinación con la Hacienda del Estado $y$ principio de solidaridad interregional, con la finalidad de garantizar la estabilidad y el desarrollo económico equilibrado a través de la política económica general que compete al Estado; así como con el objetivo, que se nos antoja decisivo, de evitar que el sistema de financiación de las Comunidades Autónomas pueda dar lugar a la creación de privilegios económicos en favor de algunas nacionalidades o regiones o pueda poner en peligro la unidad de mercado y la libre circulación de personas y bienes.

El sistema de financiación de las Comunidades Autónomas de régimen fiscal común se articula sobre un doble tipo de recursos:

1) transferencias, empleando la expresión en un sentido amplio, del Estado (participación en los impuestos estatales no cedidos, Fondo de Compensación interterritorial, asignaciones de nivelación).

2) recursos procedentes del sistema financiero propio de cada Comunidad Autónoma (tributos propios, deuda pública, ingresos patrimoniales...).

En principio, este sistema mixto de financiación de las Comunidades Autónomas no supone desconocer o negar su autonomía pues, como ha señalado el Tribunal Constitucional, la autonomia financiera no significa autofinanciación, no puede identificarse con la atribụción exclusiva de una autonomía tributaria y patrimonial, sino que lo que exige necesariamente es que las Comunidades Autónomas tengan medios suficientes para el satisfactorio cumplimiento de sus fines, aun cuando esos medios no sean en su totalidad medios propios. Ahora bien, siendo esto cierto, no es menos cierto que una excesiva dependencia de las Haciendas Autonómicas de las transferencias del Estado da lugar a dos tipos de problemas diferentes.

De una parte, ello puede redundar en menoscabo de la autonomía política y administrativa de las Comunidades Autónomas, que pueden verse condicionadas por las exigencias que les imponga el Estado como condición para realizar las transferencias dinerarias. De otra parte, esa excesiva dependencia de la Hacienda Autonómica respecto de la Hacienda del 
Estado puede afectar a la eficiencia en la utilización de los recursos públicos. Y ello, por dos razones. Porque se crean ilusiones financieras en los ciudadanos que al observar que la presión fiscal autonómica es baja, desconociendo que el presupuesto de su Comunidad Autónoma se financia en gran medida con recursos procedentes del Estado, se representan la idea de que los servicios públicos ofrecidos por la Administración Autonómica son de bajo coste, lo que puede llevarle a un uso excesivo, inadecuado e incluso abusivo de dichos servicios, lo que produce, naturalmente un aumento del gasto público que alguien tendrá que pagar en última instancia. La segunda razón que permite explicar por qué una hacienda territorial que se nutra excesivamente de transferencias estatales genera el peligro de una falta de racionalidad $y$ eficiencia en la asignación de los recursos públicos, es que una Administración que tiene la competencia para gastar los recursos públicos que no ha tenido que recaudar, propende con mayor facilidad a la expansión desmesurada del gasto público, asumiendo las demandas de prestación de servicios públicos que luego no va a poder financiar si no es reclamando mayores transferencias del Estado. $Y$ en una hacienda autonómica de transferencias, el gobierno territorial propenderá a ese comportamiento despilfarrador tratando de aprovechar la mala información de los ciudadanos-contribuyentes-consumidores de bienes y servicios públicos que desconocen el verdadero coste de las decisiones financieras de las autoridades autonómicas. En definitiva, como ha dicho RODRÍGUEZ BEREIJO «una hacienda de transferencias propende más fácilmente a convertirse en una hacienda parasitaria caracterizada por la despreocupación sobre el control de los contribuyentes y la gestión tributaria, y sobre la generalización en el reparto de la carga fiscal; la irresponsabilidad fiscal respecto de las decisiones y demandas de gasto público y una mala asignación de los recursos públicos; la ausencia de una relación entre la hacienda autonómica y sus propios contribuyentes, que repercutirá negativamente en la educación tributaria de los ciudadanos».

Por ello, el aumento del volumen del gasto público cuya decisión corresponde a las Comunidades Autónomas como consecuencia del proceso de descentralización del gasto, ha de ir acompañado de un proceso de descentralización de los ingresos públicos, en el que aumente la responsabilidad fiscal de las Comunidades Autónomas sobre los medios necesarios para la financiación del gasto que realizan.

No se trata de que las haciendas autonómicas se autofinancien, sino de que asuman el grado de responsabilidad fiscal que corresponda al grado de desarrollo de sus servicios, y sin perjuicio de que continúen, naturalmente, los mecanismos financieros de transferencias del Estado a las haciendas subcentrales, pero fundamentalmente en orden a desarrollar el principio de solidaridad y a corregir los desequilibrios económicos regionales. 
Pues bien, el examen de los ingresos que generaron las diferentes fuentes de financiación de las Comunidades Autónomas en 1989 pone claramente de manifiesto el marcado carácter de hacienda de transferencias de la Hacienda Autonómica.

El total de ingresos destinados para la financiación de los gastos de las Comunidades Autónomas ascendió en 1989 a la cifra de $4.047 .195 \mathrm{mi}-$ llones de pesetas, según datos referidos a 1989, y publicados por la Dirección General de Coordinación con las Haciendas Territoriales.

La parte más cuantiosa de los ingresos corresponde a las transferencias, con un 74,16 por 100 del total $(65,14$ por 100 corrientes y 9,02 por 100 de capital). Estas transferencias engloban la participación de las Comunidades Autónomas en los ingresos del Estado, las asignaciones correspondientes al Fondo de compensación Interterritorial, así como la participación de las Corporaciones Locales en los tributos del Estado en aquellas Comunidades Autónomas que reflejen estos flujos financieros en sus presupuestos.

Le siguen en importancia los ingresos tributarios, con un 15,11 por $100 \mathrm{del}$ presupuesto total (Impuestos directos, 3,03 por 100; impuestos indirectos 6,38 por 100 y Tasas y otros ingresos, 5,70 por 100). Conviene subrayar que dentro de estos ingresos se incluyen tanto los tributos autonómicos propios como los tributos cedidos. Este dato es importante porque, en cierto modo, los tributos cedidos participan de los problemas que generan las transferencias puesto que, en cuanto son tributos creados y regulados por el Estado, pueden crear ciertos espejismos tributarios en la medida en que los contribuyentes los identifican con el gobierno central y, sin embargo, su recaudación, total o parcialmente, corresponde a la Comunidad Autónoma.

A continuación con el 7,95 por 100 del total se encuentran los ingresos por endeudamiento originados por emisión de deuda, fianzas, depósitos y préstamos recibidos.

El resto de los ingresos corresponde a otros capítulos como activos financieros, ingresos patrimoniales, etc.

Por otra parte, la suma de los Presupuestos de las Comunidades Autónomas ha pasado de un total de 1.349 .790 millones de pesetas en 1984 , a 4.047.195 millones de pesetas en 1989, lo que supone una tasa de incremento del 199,8 por 100 en el período 1984-1989.

Todas estas cifras no hacen sino avalar la necesidad de aumentar la 
responsabilidad fiscal de las Comunidades Autónomas, siendo por tanto obligado que el crecimiento en el grado de descentralización del gasto público, que vamos a examinar a continuación, vaya acompañado de un aumento en el grado de descentralización de los ingresos públicos.

\section{LA DESCENTRALIZACIÓN DEL GASTO PÚBLICO}

No obstante el relativo grado de inconcreción acerca de cuál sea el nivel óptimo de descentralización en España, lo cual es, bajo nuestro punto de vista, una cuestión esencial para poder terminar de perfilar el Estado descentralizado que ha establecido la Constitución de 1978 y que debería precisarse cuanto antes, hemos de tratar de determinar cuál es el grado actual de descentralización del sector público en nuestro país.

Con carácter general debemos poner de manifiesto que no existe un sólo indicador de la descentralización; al contrario, existen diversas aproximaciones a esta cuestión. En este sentido, las medidas del grado de descentralización se basan en criterios tales como las ratios de participación del Gobierno central y los Gobiernos subcentrales en el ingreso total del sector público, o las ratios de participación de los distintos niveles de gobierno en el gasto público total o el volumen de transferencias y subvenciones del Estado a las Entidades territoriales Menores, etc.

Lógicamente, la utilización de una magnitud determinada conducirá a un resultado concreto; sin embargo, el parámetro que goza de mayor difusión es el de la distribución del gasto público total entre los diferentes niveles de gobierno.

Tomando como referencia, por razones de proximidad, países de gobiernos democráticos, económicamente desarrollados, basados en la economía de mercado y con un peso significativo del sector público en la economía nacional, la primera conclusión que se extrae es la falta de un patrón uniforme sobre el grado de descentralización, aun cuando cabria apreciar una tendencia descentralizadora desde los años cuarenta hasta nuestros días, con una inflexión en los setenta debido a las consecuencias de la crisis económica de esos años, que produjo un cambio en el papel del sector público.

Traduciendo a cifras concretas el criterio de la participación del Gobierno Central y los Gobiernos Subcentrales en el gasto público total como medida de la descentralización, el informe de la Comisión de Expertos so- 
bre Financiación de las Comunidades Autónomas de 1981 sostenía que "desde la situación de una hacienda centralizada que canaliza el 80 por 100 del gasto público total frente a un 20 por 100 en las haciendas locales, al final del proceso autonómico la Hacienda del Estado llevará a cabo solamente algo más del 50 por 100 del gasto total, distribuyéndose el otro 50 por 100 por partes aproximadamente iguales entre las Comunidades Autónomas y las Haciendas Locales".

La opinión de que esas cifras del 50,25 y 25 por 100 representen el reparto ideal del gasto público total, teniendo en cuenta la estructuración del Estado español en tres niveles territoriales y la previsible distribución efectiva de competencias que se producirá cuando finalice la vertebración del mismo, así como la tendencia de los países de nuestro entorno, es una opinión sumamente extendida, y es, por ejemplo, el criterios formulado por la IV Asamblea General de la Federación Española de Municipios y Provincias.

La tendencia que manifiesta actualmente el Sector público español es el de un constante aumento del grado de descentralización, especialmente en favor de las Comunidades Autónomas, y menor respeto a las Corporaciones Locales, que todavía se encuentran lejos de ese ansiado 25 por 100.

En efecto, según datos del Ministerio de Economía y Hacienda, el gasto público consolidado, excluidas las prestaciones asistenciales de la Seguridad Social y las clases pasivas, ofrece en 1989 la siguiente distribución: Estado, 63,8 por 100; Comunidades Autónomas, 21,4 por 100 y Corporaciones Locales, 14,8 por 100.

Es decir, en seis años, se ha producido un descenso de 10 puntos en el grado de centralización, pero mientras las Comunidades Autónomas administran el 21,4 por 100 del gasto público, las Corporaciones Locales sólo lo hacen del 14,8 por 100. La conclusión que se extrae de estas cifras es la necesidad de continuar en el proceso de descentralización del gasto, pero particularmente en favor de los Entes Locales.

\section{CONCLUSIONES}

La Constitución establece las líneas básicas del sistema de financiación de las Comunidades Autónomas enumerando sus recursos en el artículo 157. 
Esa relación de recursos financieros es limitativa, como se desprende de la expresión "estarán constituidos por», que figura en el precitado artículo. No es posible, por tanto, establecer otros distintos de los enumerados ni prescindir de alguno de ellos.

Ello puede suponer un obstáculo, porque puede significar una cierta rigidez en el sistema de financiación de las Comunidades Autónomas de tal forma que la evolución y desarrollo de unos entes nuevos, como son las Administraciones autonómicas, puedan verse obstaculizados desde el punto de vista de su respaldo financiero.

Ahora bien, esta preocupación inicial se disipa teniendo en cuenta el carácter abierto o flexible, en cuanto a su contenido concreto, del modelo constitucional de financiación de las Comunidades Autónomas, lo que, por otra parte, es coherente con la esencia de la Constitución como Ley Fundamental que ha de establecer las líneas maestras del sistema, dejando al legislador la concreción del mismo.

En otras palabras, la normativa constitucional relativa al sistema de financiación autonómica constituye un marco normativo general que permite, sin necesidad de modificarlo, adaptar dicho sistema en el sentido que se estime más conveniente, en función del grado de desarrollo autonómico.

Por ello, nos parece satisfactoria la regulación constitucional, desde este punto de vista. En cambio, lo que no ha sido satisfactorio ha sido el desarrollo de dicho sistema, en especial en lo que se refiere al escaso nivel de autofinanciación de las Comunidades Autónomas, y ello dicho sea sin olvidar otras deficiencias más concretas pero también importantes, como la no puesta en funcionamiento de las Asignaciones de Nivelación, del artículo 158.1 de la Constitución. 